\title{
Berkeley dispute festers over biotech deal
}

[SAN DIEGO] A \$25 million plant research contract with the life-sciences company Novartis is continuing to stir controversy at the University of California at Berkeley (UCB).

Some faculty and graduate students at the university's College of Natural Resources are deeply concerned about the arrangement's propriety and its potential impact on academic freedom. They are planning to ask the state legislature to address the issue.

The contract took effect last November (see Nature 396, 5; 1998). Its supporters, and Novartis spokespeople, say the agreement is a great advantage for the college, faculty and students. College officials say they are unaware of any inappropriate activity associated with the contract.

But critics say academic research may already be inappropriately affected. They point out that at least one graduate student has left a doctoral programme in part because of the deal. They claim that both students and faculty members feel intimidated about voicing their concerns.

"Before the Novartis deal, we had a college with diversity of opinion; now we have a divided college," said Ignacio Chapela, an assistant professor of microbial ecology, who is the elected chairman of the executive committee of the college's faculty.

The college's mainstay is research on plants and agricultural and ecological policy, in one of the world's most intensely farmed states. It is divided into four departments, including the department of plant and microbial biology that under the terms of the contract will receive $\$ 5$ million a year for five years from Novartis.

Two-thirds of the money will go into research, with one-third for indirect costs at the university and department. Much of the Novartis-funded research is expected to involve genetically modified plants and associated fields. Faculty and students are to get access to Novartis's genomic databases of information on plants.

In return, Novartis will have first right to negotiate for licences on a percentage about 30 per cent in the first year of the contract - of patentable discoveries coming from research carried out by individuals in the participating department. Twenty-nine of 32 faculty in the department have signed up to participate in the agreement. The university will retain ownership of the research results and patents.

Gordon Rausser, the dean of the college and principal architect of the Novartis deal, calls the critics' concern "silly". Regarding any move to have the state legislature examine the deal, Rausser says: "I would be delighted with any scrutiny; it will prove we enhanced and leveraged public resources."

In recent months displeasure over the

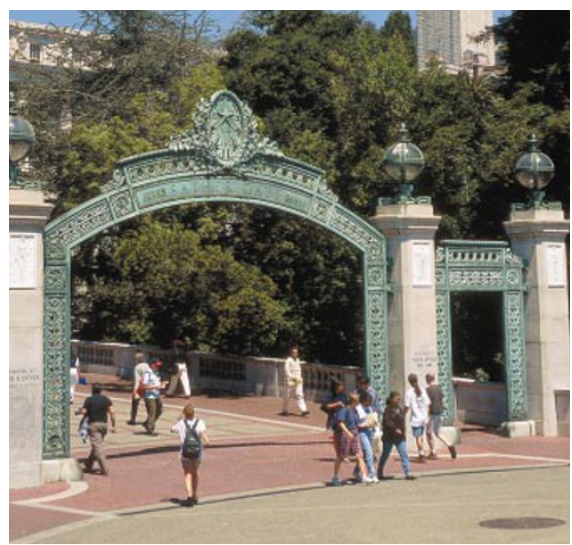

Up for sale? Some at UC Berkeley fear business deals may compromise academic freedom.

Novartis deal has erupted in a number of Berkeley campus quarters, including an article in the February issue of the UCB alumni magazine, California Monthly, by Robert Berring, the Walter Perry Johnson Professor at UCB's School of Law.

"We must ask at what point does the university bargain away so much of itself that is ceases to be the university and becomes a partner of the private sector?" wrote Berring in the article. "If the private sector begins to play a role in setting research priorities, if it gets built into the budget, something very fundamental has changed.'

The current issue of the magazine includes an article by Rausser, supporting the Novartis deal, that is seen as a sharp response to Berring.

"In the final analysis, (UC) Berkeley is a public asset of immense value," writes Rausser. "So long as our culture is maintained, this value will be enhanced, not diminished, when we work creatively in collaboration with other institutions, including private companies."

There is some evidence that the nascent Novartis deal is already affecting the university culture. Susan West, a doctoral candidate at the college, claims that the Novartis deal was "the clincher" in prompting her to drop out of the programme after completing her first term in December.

"I was uncomfortable with it," says West, who was pursuing research into arctic terns after completing a Fulbright Fellowship in Iceland. "It impugned the entire college. Do they really believe that [ $\$ 25$ million] will not swing the balance?"

There are unconfirmed reports that, during a recent oral exam on a doctoral student's thesis, the student was encouraged to pursue a line of research with Novartis. Several college faculty have said that this sort of intrusion into the academic process, if it did take place as described, was clearly inappropriate. Rausser says that he would be concerned about such an interaction, but that he is unaware of any such report. RexDalton

\section{Embattled neuroscientist wins US support}

[MUNICH] Forty-six top US neuroscientists have written an open letter to politicians and university professors in the German state of Bremen protesting at the treatment of a leading neuroscientist who has received a string of threats from animal-rights activists.

The signatories to the letter include the Nobel laureates Francis Crick and David Hubel. They say that they endorse the basic research into cognition that Andreas Kreiter is carrying out using macaque monkeys, and stress that the work could have long-term importance for treating psychiatric and neurological disorders.

The letter also attacks the lack of local support for Kreiter, who has been continually criticized both by animal rights activists and by some of his colleagues since his arrival in Bremen in 1997 (see Nature 395, 505; 1998).

"It is perhaps understandable that some individuals ... can be influenced by the narrow ideology and polemics of the animal rights organizations," says the letter. "We are astonished, however, that substantial numbers of academicians, government representatives and journalists appear sympathetic to the efforts of these organizations to prevent Professor Kreiter and others from performing their research."

Last year, more than 100 professors at the University of Bremen - including a number of biologists - signed a letter calling for Kreiter's research to be terminated. The letter was sent to all members of the university members and to the government of Bremen.

But Hans Flohr, director of the University of Bremen's brain research institute, says the letter is a "great help". He adds: "In a small state like Bremen, politics is very close to the people, and politicians feel very much the influence of pressure groups."

The powerful international voice in support of Kreiter's research is a strong counterbalance to this pressure, he says.

Wolfgang Appel, president of the German Animal Protection Association, says he understands that scientists working in the same field would want to support each other, but says he could gather "hundreds of other scientists who could give equally well-argued cases against the value of Kreiter's primate work". 